\title{
Manejo anestésico de paciente con Rendu Osler Weber
}

\author{
Dayoub AL. ${ }^{1}$, Szakura MH. ${ }^{1}$, Mazzini HA. ${ }^{1}$, D\&apos;Amato R. ${ }^{1}$ \\ 1 Sanatorio Guemes, CABA, Argentina.
}

La enfermedad de Rendu-Osler-Weber, también llamada Telangiectasia Hemorrágica Hereditaria (THH) es una enfermedad genética rara de tipo autosómica dominante con una frecuencia entre 1:5.000 y 1:8.000. Se caracteriza por epistaxis, anemia ferropénica asociado a telangiectasias mucocutáneas, MAVs y fístulas en el pulmón, hígado, tracto gastrointestinal.

Caso clínico: Mujer de 63 años G2P0C2A0, IMC 24. Como antecedentes personales se destacan THH, asma, EPOC e hipotiroidismo. Alérgica al Ibuprofeno y Pridinol. Consulta por lesión de $4 \times 5 \mathrm{~cm}$, duro-elástica, móvil, no dolorosa en escápula derecha. Presentaba episodios recurrentes de epistaxis y disnea. Laboratorio: Hto: 27,2\%, Hb: 7,8 g/dl, VCM: $65,4 \mathrm{ft} / 1$.

Evaluación preoperatoria: Neumología indicó Vilanterol, Fluticasona, TAC de tórax y espirometría. La TAC informó tractos fibrosos compatibles con EPOC. La espirometría del informó patrón obstructivo, con franca mejoría luego de modificar la medicación. Se indicaron broncodilatadores y corticoides EV pre y postquirúrgicos.

Hematología optimizó el hematocrito con sulfato ferroso obteniendo un valor de $\mathrm{Hb}$ de 12,1 g/dl. Indicaron ácido para el postoperatorio.

Anestesiología evaluó la vía aérea, no presentaba parámetros de dificultad. Se evidenciaron múltiples telangiectasias en labios y cavidad oral. En la TAC de tórax no se evidenciaron MAVs en vía aérea ni en pulmón.

Prodecimiento: Al momento del procedimiento se encontraba en tratamiento con Levotiroxina, Budesonide, Fluticasona, Vilanterol, Montelukast, Salbutamol, Sulfato Ferroso y Escitalopram. Se realizó anestesia general balanceada (Sevoflurane 1\% + Remifentanilo 0,4 mcg/kg), no presentó complicaciones en la intubación (FiO2: 50\%, TE: 6,5 c/ balon, Vt: 7 ml/kg, FR: 12, PEEP: 5). En el intraoperatorio la paciente se mantuvo hemodinámicamente estable, con mínimo sangrado. Para manejo del dolor se utilizó Tramadol $100 \mathrm{mg}$ con profilaxis antiemética. En el postoperatorio inmediato fue observada en Internación Quirúrgica Breve (IQB) y dada de alta el mismo día. Se le indicó continuar con el Ácido Tranexámico VO por $48 \mathrm{~h}$.

Discusión: La enfermedad de Rendu Osler Weber predispone a un mayor sangrado por su fisiopatología. Esto obliga a realizar una valoración diagnóstica prequirúrgica según la complejidad del procedimiento, siempre que no se trate de una urgencia. Los criterios de Curaçao (Figura. 1) son utilizados para el diagnóstico de la patología.

A raíz del caso presentado, nuestro servicio de anestesiología sugiere el siguiente manejo para una posible intervención quirúrgica.

https://doi.org/10.25237/congresoclasa2019.48 